\title{
Neonatal hypothermia and associated factors among neonates admitted to neonatal intensive care unit of public hospitals in Addis Ababa, Ethiopia
}

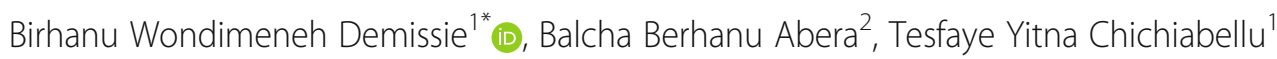
and Feleke Hailemichael Astawesegn ${ }^{3}$

\begin{abstract}
Background: Neonatal hypothermia is a worldwide problem and an important contributing factor for Neonatal morbidity and mortality especially in developing countries. High prevalence of hypothermia has been reported from countries with the highest burden of Neonatal mortality. So the aim of this study was to assess the prevalence of Neonatal hypothermia and associated factors among newborn admitted to Neonatal Intensive Care Unit of Public Hospitals in Addis Ababa.

Methods: An institutional based cross-sectional study was conducted from March 30 to April 30, 2016, in Public Hospitals in Addis Ababa and based on admission rate a total of 356 Neonates with their mother paired were enrolled for the study. Axillary temperate of the newborn was measured by a digital thermometer at the point of admission. Multivariate binary logistic regression, with 95\% confidence interval and a $p$-value $<0.05$ was used to identify variables which had a significant association.

Results: The prevalence of Neonatal hypothermia in the study area was $64 \%$. Preterm delivery (AOR $=4.81,95 \%$ $\mathrm{Cl}: 2.67,8.64)$, age of Neonate $\leq 24 \mathrm{~h}$ old $(\mathrm{AOR}=2.26,95 \% \mathrm{Cl}: 1.27,4.03)$, no skin to skin contact with their mother immediately after delivery ( $\mathrm{AOR}=4.39,95 \% \mathrm{Cl}: 2.38,8.11)$, delayed initiation of breastfeeding ( $\mathrm{AOR}=3.72,95 \% \mathrm{Cl}$ : $2.07,6.65)$ and resuscitation at birth $(\mathrm{AOR}=3.65,95 \% \mathrm{Cl}: 1.52,8.78)$ were significantly associated with hypothermia.

Conclusions: The prevalence of Neonatal hypothermia in the study area was high. Preterm delivery, age $\leq 24 \mathrm{~h}$ old, no skin to skin contact immediately after delivery, delayed initiation of breastfeeding and resuscitation at birth were independent predictors of Neonatal hypothermia. Therefore attention is needed for thermal care of preterm newborn and use of low-cost thermal protection principles of warm chain especially on early initiation of breastfeeding, skin to skin contact immediately after delivery and warm resuscitation.
\end{abstract}

Keywords: Hypothermia, Newborn, NICU, Addis Ababa

\footnotetext{
* Correspondence: birhanuwondimeneh@gmail.com

'Department of Nursing, College of Health Sciences and Medicine, Wolaita

Sodo University, Sodo, Ethiopia

Full list of author information is available at the end of the article
}

(c) The Author(s). 2018 Open Access This article is distributed under the terms of the Creative Commons Attribution 4.0 International License (http://creativecommons.org/licenses/by/4.0/), which permits unrestricted use, distribution, and reproduction in any medium, provided you give appropriate credit to the original author(s) and the source, provide a link to the Creative Commons license, and indicate if changes were made. The Creative Commons Public Domain Dedication waiver (http://creativecommons.org/publicdomain/zero/1.0/) applies to the data made available in this article, unless otherwise stated. 


\section{Background}

World Health Organization (WHO) defined Neonatal hypothermia as an axillary temperature less than $36.5^{\circ} \mathrm{C}$. Reduction of thermal stability has a long-term physiologic effect that leads to, death due to hypoxia, and hypotension [1]. Globally an estimated of four million newborns die within the first four weeks of life, which accounts $2 / 3$ rd of all deaths in the first year of life and $40 \%$ of under five deaths. Most Neonatal deaths (99\%) arise in low and middle-income countries [2, 3]. In Ethiopia also there is high Neonatal mortality, 37 deaths per 1000 live birth [4].

Hypothermia is one of the important causes for Neonatal death and morbidity in developing countries, which increases mortality by five times, and recent studies showed that every $1{ }^{\circ} \mathrm{C}$ decrement of body temperature increases mortality by $80 \%[2,5,6]$. The prevalence is high among countries with the highest burden of Neonatal mortality [7]. It is a problem of both home delivered (32 - 85\%) and institutional delivery (11 to 90\%) [8]. A study in Bangladesh reported 34\% of Neonates had hypothermia out of NICU admission [9]. Reports in developing country show that greater than $90 \%$ of Neonates were hypothermic (temperature less than $36.5^{\circ} \mathrm{C}$ ) and $10.7 \%$ of the newborn were at less than $35.0{ }^{\circ} \mathrm{C}[10$, 11]. In West African sub-region, a prevalence rate of $62 \%$ at the point of admission was reported [12]. In Ethiopia also there was a prevalence of hypothermia ranging from 53 to $69.8 \%[8,13]$.

Prematurity is one of the risk factors for Neonatal hypothermia and it is the leading cause of Neonatal mortality which accounts $37 \%$ of Neonatal death in Ethiopia [4]. And the prevalence of preterm birth ranges from 10 - 25.9\% $[14,15]$. Both physical characteristics and environmental factors predispose the preterm infant to hypothermia [16].

In Ethiopia lack of adequate perinatal care is one of the factors for onset of hypothermia, there is a high prevalence of home delivery which accounts $73 \%$ and Institutional deliveries accounts only $26 \%$ [17]. Low socio-economic status, poor kangaroo mother care practice, low birth weight, bathing of a newborn within $24 \mathrm{~h}$, delayed initiation of breastfeeding, a traditional practice of oil massage of Neonates and inadequate knowledge of thermal care among health workers are determinant factors for hypothermia $[2,18,19]$.

Although hypothermia is rarely a direct cause of death, it contributes to Neonatal mortality as a comorbidity of severe Neonatal infections, preterm birth, and asphyxia [8]. Mortality rate was significantly higher among hypothermic babies ( $\mathrm{RR}=2.26, \mathrm{CI}=1.14-4.48$ ).

Even though predisposing factors for hypothermia are easily preventable the problem of hypothermia remains an unanswered question and it is highly prevalent in developing nations including sub-Sahara Africa [2].
Ethiopia applies thermal care principle which is one of the components of essential newborn care (ENBC) recommended by WHO. Despite this intervention, the problem of hypothermia remains a challenge in Ethiopia $[1,20]$. And the achievement of sustainable development goal (SDG) 3 of ensuring healthy lives and promote well-being for all at all age requires a remarkable reduction of Neonatal death. Even though reduction of Neonatal hypothermia contributes to the achievement of SDG 3, it sustains as a challenge [21].

Providing ENBC including thermal care or prevention of Neonatal hypothermia is one part of nursing care, but the problem of Neonatal hypothermia remains a worldwide problem, especially in sub-Saharan Africa. Therefore, the purpose of this study was to determine the prevalence of Neonatal hypothermia and associated factors among Neonates admitted to NICU of Public Hospitals in Addis Ababa. So, this study will provide baseline data on the prevalence of Neonatal hypothermia and identification of possible factors for the onset of Neonatal hypothermia in the area will have greater input to program managers and policy makers for designing, proper implementation and evaluation programs on reduction of Neonatal mortality and improvement of newborn care to achieve SDG 3. In addition, the study will help to improve quality of newborn care in the nursing profession, specifically thermal protection, by low - tech preventive measures and early detection and referral of hypothermia.

\section{Methods}

\section{Study design and period}

An institutional based cross -sectional study design was conducted from March 30 to April 30, 2016, to determine the prevalence of Neonatal hypothermia and associated factors among Neonates admitted to Neonatal Intensive Care Unit of Public Hospitals in Addis Ababa.

\section{Study setting}

The study was conducted in six Public Hospitals in Addis Ababa, Ethiopia, that have their own NICU; namely; Tikur Anbessa Specialized Teaching Hospital that has its own Neonatal Intensive Care Unit (NICU) with an average NICU admission of 240 Neonates per month, St. Paul's Hospital Millennium Medical College with an average NICU admission of 210 Neonates per month, Yekatit 12 Hospital Medical College with an average NICU admission of 170 Neonates per month, Gandhi Memorial Specialized Hospital with an average NICU admission of 192 Neonates per month, Zewditu Memorial Hospital with an average NICU admission of 110 Neonates per month and Tirunesh Beijing General Hospital with an average NICU admission of 60 Neonates per month. The study was conducted in all Public Hospitals in Addis Ababa that has their own NICU, because the level of perinatal care given, 
standards of NICU, and accessibility of thermal prevention materials are somewhat different in each Hospital.

\section{Population}

\section{Source population}

The source populations were all Neonates who were admitted to NICU of public Hospitals in Addis Ababa.

\section{Study population}

Randomly Selected Neonates admitted to NICU of public Hospitals in Addis Ababa from March 30 to April 30, 2016, were the study population.

\section{Eligibility criteria}

\section{Inclusion criteria}

All Neonates with their mother admitted to NICU of Public Hospitals in Addis Ababa during the study period were included in the study.

\section{Sample size determination}

Sample size was calculated by using single population proportion formula:

$$
\mathrm{n}=\frac{(\mathrm{z} a / 2) 2^{*} \mathrm{pq}}{d 2}
$$

By considering $10 \%$ none response rate of participants, the final sample size was 356 .

Where $n=$ the required sample size.

$d=m$ argin of error between the sample and population $=5 \%=0.05$

$Z=s$ tandard normal distribution value at $95 \%$ confidence level

$Z \alpha / 2=1.96$ for $95 \%$ confidence interval

$p=$ Prevalence of Neonatal hypothermia (69.8\%)

from the previous study conducted in Gondar University Teaching and Referral Hospital, Northwest Ethiopia [13].

\section{Sampling technique and procedure}

There were a total of six Public Hospitals in Addis Ababa that have their own organized NICU and they have a total average number of 982 admissions to NICU per month and a total sample size of 356 Neonates were selected from the six Hospitals. Then participants was selected by using systematic random sampling technique, that is every three admission until the required sample size was obtained $(K=2.75$, approximately every 3 admissions was taken). The number of Neonates surveyed from each Hospital was allocated proportionally to the total average number of admission per month from all Hospitals.

\section{Method of data collection}

The instrument for data collection was semi-structured pre-tested questionnaire which was adopted and modified from a study conducted in Ethiopia, Gondar University Hospital, Nigeria and Uganda [12, 13, 19]. The questionnaire contains items to assess the temperature of the newborn during admission to NICU and associated factors for the onset of hypothermia (Additional file 1).

Axillary temperate of the newborn was measured for three minute by using digital thermometer (model of MT-101 MT-111) which can measure from $32.0{ }^{\circ} \mathrm{C}$ to $42.9{ }^{\circ} \mathrm{C}\left(89.6{ }^{\circ} \mathrm{F}\right.$ to $\left.109.9{ }^{\circ} \mathrm{F}\right)$ that had measurement accuracy of $\pm 0.1{ }^{\circ} \mathrm{C}$ for the temperature range of $\left(35.5{ }^{\circ} \mathrm{C}\right.$ - $42.0{ }^{\circ} \mathrm{C}$ ) and $\pm 0.2{ }^{\circ} \mathrm{C}$ for the temperature range of $\left(32.0{ }^{\circ} \mathrm{C}-35.5{ }^{\circ} \mathrm{C}\right.$ or above $\left.42.0{ }^{\circ} \mathrm{C}\right)$ at point of admission. The thermometer was disinfected by using $70 \%$ ethyl alcohol disinfectant with a damp cloth after every measure of axillary temperature of the newborn to prevent infection transmission.

And other data such as; medical diagnosis, and CPR history was collected from the chart of the newborn and socio-demographic data and obstetric history was collected from their mother by using semi-structured pre-tested questionnaire. Infrared thermometer (model of Kintrex IRT0421) with a measurement range of $\left(-60{ }^{\circ} \mathrm{C}\right.$ to $\left.50{ }^{\circ} \mathrm{C}\right)$ and measurement accuracy of $\pm 2{ }^{\circ} \mathrm{C}$ was used to measure the room temperature of the NICU. And data collection was done carefully by six BSc nurses.

\section{Study variables \\ Dependent variable}

- Neonatal hypothermia

\section{Independent variables}

1. Socio-demographic characteristics of the mother Maternal age, parity, residence, ethnicity, educational status, occupation and income.

2. Neonatal, obstetric and environmental factors of the neonate:

Age of newborn in hour, sex of newborn, low birth weight, mode of delivery, pregnancy type (single / multiple), prematurity, skin to skin contact with mother immediately after delivery, bathing before age of $24 \mathrm{~h}, \mathrm{CPR}$, delayed initiation of breastfeeding, room temperature of NICU, place of delivery, application of oil massage, obstetric complication during pregnancy and Medical diagnosis during admission.

\section{Operational definitions}

- Hypothermia: an axillary temperature of less than $36.5{ }^{\circ} \mathrm{C}$ 
- Cold stress(mild hypothermia): an axillary temperature of 36.0 to $36.4{ }^{\circ} \mathrm{C}$

- Moderate hypothermia: an axillary temperature of 32.0 to $35.9^{\circ} \mathrm{C}$

- Severe hypothermia: an axillary temperature of $<32.0^{\circ} \mathrm{C}$

- Normothermic: an axillary temperature of 36.5 to $37.5^{\circ} \mathrm{C}$

- Hyperthermia: an axillary temperature of $>37.5^{\circ} \mathrm{C}$

- Admission temperature: The first temperature obtained from neonates at admission to NICU

- Inborn: a new born that was delivered from the study Hospital

- Out born: a new born that was deliver other than the study Hospital

\section{Data quality and control}

The questionnaire was prepared in English and translated to Amharic, and back-translated into English by two language experts to check for consistency of the questionnaire. The data was collected by six BSc. nurse experts. Thermometer calibration was done for the reliability of the thermometer before using the instrument for data collection. Three day training and clear orientation were provided on the process of data collection for data collectors. A pretest was done by $5 \%$ of the study population in another Hospital three weeks before the actual data collection to evaluate the clarity of questions and validity of the instrument and reaction of respondents to the questions. Data collectors were closely monitored and guided by two MSc. nurse supervisors during data collection.

\section{Data entry and analysis}

The data was cleaned manually, coded and entered into Epi info version 3.5 and exported to SPSS version 20 software for further analysis. After coding, and entering the data to the software descriptive statistics were used to calculate the result in proportion, frequencies, cross tabulation, and measure of central tendency. Tables and graphs were used to present the result. A bivariate binary logistic regression was used to identify candidate variables for the final model (multivariate binary logistic regressions) at $p$ - value $<0.20$. Finally the independent predictors or variables which had significant association were identified by using multivariate binary logistic regressions. The cut point to declare the presence of an association between the dependent and independent variable was $p-$ value $<0.05$ or $\mathrm{AOR}, 95 \% \mathrm{CI}$.

\section{Results}

Socio - demographic characteristics

A total of 356 mothers with their neonates were included in the study with $100 \%$ response rate. The mean age of mothers was 28 years $(\mathrm{SD}=5.6)$ and more than half of the mothers were in the age group between 20 and $29(51.1 \%)$ years of age. One hundred twenty seven (35.7\%) were Oromo in ethnicity and majority of the mothers 206 (57.9\%) were Orthodox followers. Two hundred seventy six (77.5\%) were urban residents. Eighty respondents $(22.2 \%)$ were unable to read and write and $144(40.4 \%)$ of respondents were housewife. The mean monthly income of the family was 54 US dollar (SD = 11US dollar) and $117(32.9 \%)$ had a monthly income of below average. And 191 respondents (53.7\%) were primiparous (Table 1).

Table 1 Socio-demographic characteristics of mothers of neonates admitted to Neonatal Intensive Care Unit of Public Hospitals in Addis Ababa, Ethiopia, 2016 [ $n=356]$

\begin{tabular}{|c|c|c|c|}
\hline Variables & Categories & Frequency & Percentage (\%) \\
\hline \multirow{4}{*}{$\begin{array}{l}\text { Age of mother } \\
\text { (years) }\end{array}$} & $15-19$ & 17 & 4.8 \\
\hline & $20-29$ & 182 & 51.1 \\
\hline & $30-39$ & 145 & 40.7 \\
\hline & $40-49$ & 12 & 3.4 \\
\hline \multirow[t]{5}{*}{ Ethnicity } & Amhara & 121 & 34.0 \\
\hline & Tigre & 55 & 15.4 \\
\hline & Oromo & 127 & 35.7 \\
\hline & Gurage & 37 & 10.4 \\
\hline & Other & 16 & 4.5 \\
\hline \multirow[t]{4}{*}{ Religion } & Orthodox & 206 & 57.9 \\
\hline & Protestant & 59 & 16.6 \\
\hline & Muslim & 88 & 24.7 \\
\hline & Other & 3 & 0.8 \\
\hline \multirow[t]{2}{*}{ Residence } & Urban & 276 & 77.5 \\
\hline & Rural & 80 & 22.5 \\
\hline \multirow[t]{4}{*}{ Educational status } & $\begin{array}{l}\text { Unable to read } \\
\text { and write }\end{array}$ & 80 & 22.5 \\
\hline & Primary school & 77 & 21.6 \\
\hline & Secondary school & 102 & 28.7 \\
\hline & Diploma and above & 97 & 27.2 \\
\hline \multirow[t]{5}{*}{ Occupation } & House wife & 144 & 40.4 \\
\hline & Government employ & 79 & 22.2 \\
\hline & Private business & 92 & 25.8 \\
\hline & Student & 27 & 7.6 \\
\hline & Farmer & 14 & 3.9 \\
\hline \multirow{3}{*}{$\begin{array}{l}\text { Monthly income } \\
\text { of the family }\end{array}$} & Below average & 117 & 32.9 \\
\hline & $\begin{array}{l}\text { Average } \\
\text { (43-65 US dollar) }\end{array}$ & 129 & 36.2 \\
\hline & Above average & 110 & 30.9 \\
\hline \multirow[t]{2}{*}{ Parity } & Primiparous & 191 & 53.7 \\
\hline & Multiparous & 165 & 46.3 \\
\hline
\end{tabular}




\section{Neonatal factors}

Majority of Neonates were males 204 (57.3\%) and the median age of the newborn was $3 \mathrm{~h}$. And most of the neonates $233(65.4 \%)$ were in the age group of $\leq 24 \mathrm{~h}$. The mean birth weight was $2440 \mathrm{~g}$ (SD $721 \mathrm{~g}$ ). More than half $183(51.4 \%)$ of the Neonates had birth weight $\geq 2500 \mathrm{~g}$. The mean gestational age (GA) was 36 weeks \pm 2.8 weeks, most of them, $202(56.7 \%)$ were with GA $<37$ weeks. Only 126 (35.4\%) of Neonates had early initiation of breastfeeding within one hour after birth. Eighty four (23.6\%) had received resuscitation $(\mathrm{CPR})$ during birth (Table 2).

\section{Obstetric and environmental factors}

Most of the pregnancies 311 (87.4\%) were single and the majority of Neonates 286 (80.3\%) were born without any obstetric complication. More than half 213 (59.8\%) were delivered through SVD. Sixty five (18.3\%) of the newborn were bathed before $24 \mathrm{~h}$ old and more than half of Neonates 188 (52.8\%) had no skin to skin contact immediately after birth. And 41 (11.5\%) had Oil massage of the skin after birth. One hundred seventy (47.8\%) were out born neonates and of them, nine (2.5\%) delivered at home. More than half 190 (53.4\%) deliver during day time. Majority of Neonates 329 (92.4\%) were admitted to NICU at room Temperature $\geq 25^{\circ} \mathrm{C}$ (Table 3).

Table 2 Neonatal characteristics of respondents among Neonates admitted to Neonatal Intensive Care Unit of Public Hospitals in Addis Ababa, Ethiopia, 2016 [ $n=356$ ]

\begin{tabular}{llll}
\hline Variables & Categories & Frequency & Percentage (\%) \\
\hline Age of Newborn (hour) & $\leq 24$ & 233 & 65.4 \\
& $24-72$ & 60 & 16.9 \\
& $>72$ & 63 & 17.7 \\
Sex of new born & Male & 204 & 57.3 \\
& Female & 152 & 42.7 \\
Birth weight(grams) & $<1000$ & 10 & 2.8 \\
& $1000-1499$ & 32 & 9.0 \\
& $1500-2499$ & 131 & 36.8 \\
& $2500-4000$ & 179 & 50.3 \\
& $>4000$ & 4 & 1.1 \\
Gestational age (weeks) & $<28$ weeks & 2 & 0.6 \\
& $28-<32$ weeks & 25 & 7.0 \\
& $32-<37$ weeks & 175 & 49.2 \\
& $37-42$ weeks & 152 & 42.7 \\
& $>42$ weeks & 2 & .6 \\
Received CPR during birth & Yes & 126 & 35.4 \\
& No & 230 & 64.6 \\
Started breast feeding & Yes & 232 & 76.4 \\
birth & & &
\end{tabular}

Table 3 Obstetric and Environmental characteristics of respondents among Neonates admitted to Neonatal Intensive Care Unit of Public Hospitals in Addis Ababa, Ethiopia, $2016[n=356]$

\begin{tabular}{|c|c|c|c|}
\hline Variables & Categories & Frequency & Percentage (\%) \\
\hline \multirow{2}{*}{$\begin{array}{l}\text { Obstetric complication } \\
\text { during pregnancy }\end{array}$} & Yes & 70 & 19.7 \\
\hline & No & 286 & 80.3 \\
\hline \multirow[t]{3}{*}{ pregnancy type } & Single & 311 & 87.4 \\
\hline & Twine & 41 & 11.5 \\
\hline & Triple & 4 & 1.1 \\
\hline \multirow[t]{3}{*}{ Mode of delivery } & SVD & 213 & 59.8 \\
\hline & Instrumental & 32 & 9.0 \\
\hline & $\mathrm{C} / \mathrm{S}$ & 111 & 31.2 \\
\hline \multirow{2}{*}{$\begin{array}{l}\text { skin to skin contact } \\
\text { immediately after } \\
\text { delivery }\end{array}$} & Yes & 168 & 47.2 \\
\hline & No & 188 & 52.8 \\
\hline \multirow[t]{2}{*}{ Place of delivery } & Inborn & 186 & 52.2 \\
\hline & Out born & 170 & 47.8 \\
\hline \multirow{6}{*}{$\begin{array}{l}\text { setting for out born } \\
\text { delivery }\end{array}$} & Missing (Inborn) & 186 & 52.2 \\
\hline & Other Hospital & 69 & 19.4 \\
\hline & Health Centre & 76 & 21.3 \\
\hline & $\begin{array}{l}\text { Private health } \\
\text { facility }\end{array}$ & 13 & 3.7 \\
\hline & $\begin{array}{l}\text { Traditional birth } \\
\text { center }\end{array}$ & 3 & 0.8 \\
\hline & Homes & 9 & 2.5 \\
\hline \multirow{2}{*}{$\begin{array}{l}\text { Oil massage of the skin } \\
\text { immediately after birth }\end{array}$} & Yes & 41 & 11.5 \\
\hline & No & 315 & 88.5 \\
\hline \multirow{2}{*}{$\begin{array}{l}\text { Bathed the new born } \\
\text { before } 24 \mathrm{~h} \text { old }\end{array}$} & Yes & 65 & 18.3 \\
\hline & No & 291 & 81.7 \\
\hline \multirow[t]{2}{*}{ Time of delivery } & Day time & 190 & 53.4 \\
\hline & Night time & 166 & 46.6 \\
\hline $\begin{array}{l}\text { Room Temperature } \\
\text { of NICU }\end{array}$ & $<25^{\circ} \mathrm{C}$ & 27 & 7.6 \\
\hline
\end{tabular}

\section{Medical diagnosis of the neonate}

Medical diagnoses during admission were reviewed from medical record of the newborn and 116 (32.6\%) were admitted for the reason of respiratory distress, 173 (48.6\%) diagnosed as low birth weight and $202(56.7 \%)$ were diagnosed as preterm, and $84(23.6 \%)$ diagnoses as perinatal asphyxia (Table 4).

\section{The prevalence of neonatal hypothermia}

The prevalence of neonatal hypothermia among Neonates admitted to Neonatal Intensive Care Unit of Public Hospitals in Addis Ababa was 228 (64\%). Among them, more than half $184(80.7 \%)$ were moderate hypothermic and the remaining 44 (19.3\%) were mild hypothermic babies (Fig. 1). 
Table 4 Medical diagnoses of neonates during admission among Neonates admitted to Neonatal Intensive Care Unit of Public Hospitals in Addis Ababa, Ethiopia, 2016 [ $n=356]$

\begin{tabular}{llll}
\hline Variable & Categories & Frequency & Percentage (\%) \\
\hline Diagnosis during & Respiratory distress & 116 & 32.6 \\
Admission & Preterm & 202 & 56.7 \\
& Jaundice & 55 & 15.4 \\
& Sepsis & 83 & 23.3 \\
& LBW & 173 & 48.6 \\
& Perinatal asphyxia & 84 & 23.6 \\
& Congenital anomaly & 35 & 9.8 \\
& Meconium aspiration & 22 & 6.2 \\
& syndrome & & \\
& Small for gestational age & 15 & 4.2 \\
& hypoglycemia & 15 & 4.2 \\
& Other & 16 & 4.5 \\
& The total cumulative frequency for diagnosis \\
& is greater than 100\% because the Neonate \\
& may have more than one clinical diagnosis \\
& during admission.
\end{tabular}

And the prevalence of hypothermia was high among preterm 155 (76.7\%), low birth weight 127 (73.4\%), age $\leq 24 \mathrm{~h} 171(73.4 \%)$, and among out born delivery 112 (65.9\%) (Fig. 2).

\section{Factors associated with neonatal hypothermia}

In bivariate logistic regression analysis the following factors were significantly associated with hypothermia; age of newborn $\leq 24 \mathrm{~h}$ old, low birth weight, preterm delivery, no skin to skin contact to their mother immediately after delivery, no early initiation of breastfeeding within one hour, resuscitation at birth $(\mathrm{CPR})$, obstetric complication during pregnancy, multiple Pregnancy and night-time delivery. Then those variables which are significant on bivariate analysis were entered to multiple logistic regressions to see independent predictors.

Accordingly, Neonates with the age of $\leq 24$ h old were 2 times more likely to have hypothermia when compared to age greater than $24 \mathrm{~h}(\mathrm{AOR}=2.26,95 \% \mathrm{CI}: 1.27,4.03)$.

Preterm Neonates were 4.8 times more likely to have hypothermia when compared to term delivery $(\mathrm{AOR}=$ 4.81, 95\% CI: $2.67,8.64$ ). And newborn who had no skin to skin contact to their mother immediately after delivery were 4.3 times more likely to be hypothermic when compared to those who have skin to skin contact $(\mathrm{AOR}=4.39,95 \%$ CI: 2.38, 8.11). Those Neonates who had no early initiation of breastfeeding within one hour after birth were 3.7 times more likely to develop hypothermia when compared to those who have started within one hour after birth (AOR $=3.72,95 \% \mathrm{CI}$ : 2.07 , 6.65). And Neonates who had resuscitation at birth (CPR) were 3.6 times more likely to be hypothermic when compared to those who had no resuscitation $(\mathrm{AOR}=3.65,95 \% \mathrm{CI}: 1.52,8.78)$ (Table 5$)$.

\section{Discussion}

The prevalence of Neonatal hypothermia among newborn in this study was $64 \%$. This was almost similar with a study conducted in Nigeria (62\%) [12], in Bahir Dar, Ethiopia (67\%) [22] and Gondar, Northwest Ethiopia (69.8\%) [13]. And it was lower than a study conducted in Nepal (92.3\%) [10], Zimbabwe (85\%) [8] and Uganda (83\%) [19]. But it was higher than a study conducted in South Africa (21\%) [23], Bangladesh (34\%) [9] and Pakistan (49.5\%) [24]. This variation might be due to the difference in temperature measurement site,






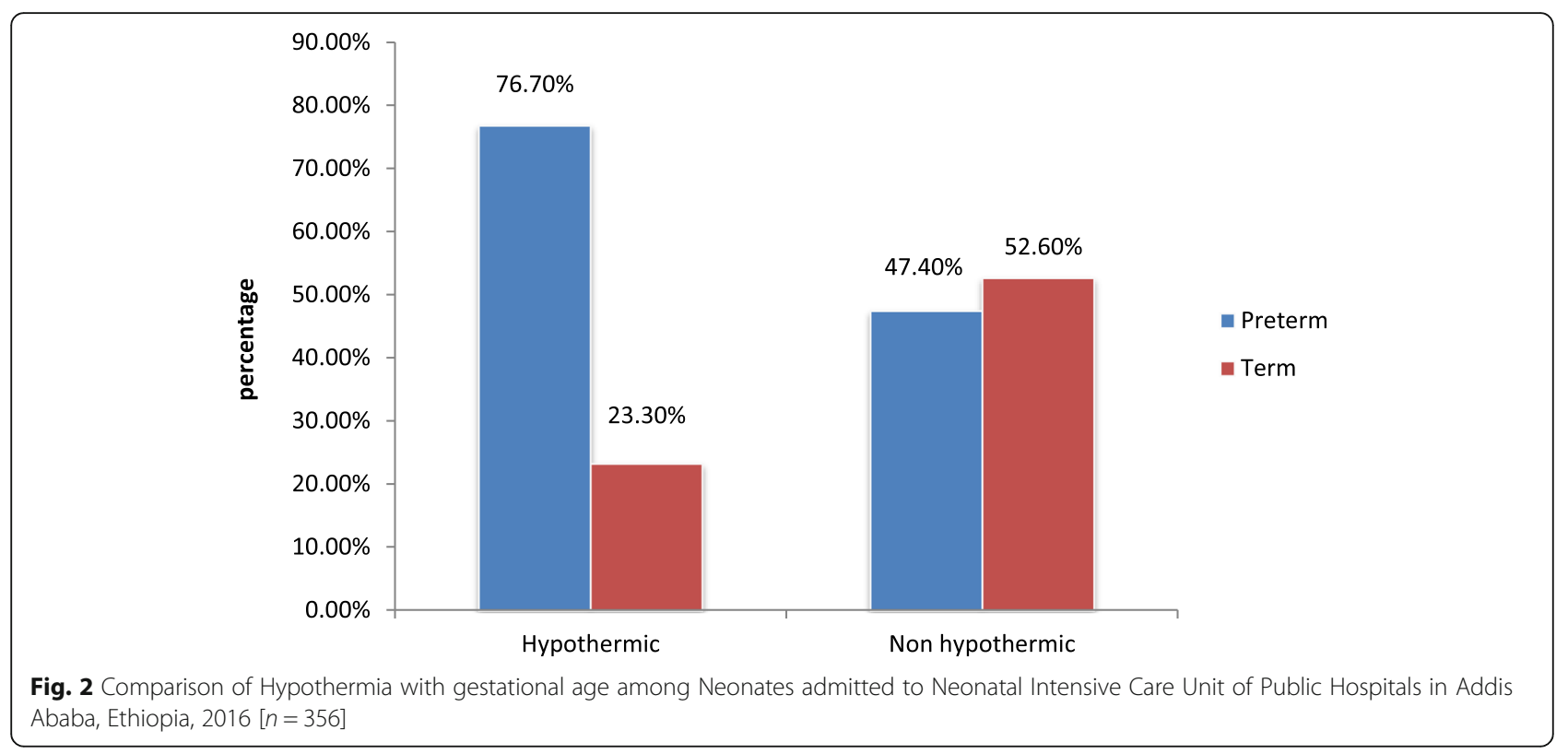

ecological, economic and cultural difference between the study areas.

There was high prevalence of hypothermia among out born delivery (65.9\%); this might be due to lack of proper thermal care practice during inter-facility transportation. Neonates are transported from ward to ward or to other Hospital without proper wrapping. This finding was higher than a study done in Bangladesh which was $43 \%$ for out born and $22 \%$ for inborn but lower than Nigeria which was $90.9 \%$ for out born and $61.1 \%$ for inborn $[9,12,23]$. This might be due to the difference in inter-Hospital transport thermal care services, distance traveled to the hospital and economical difference.

This study revealed that Neonates with the age of $24 \mathrm{~h}$ old or less were 2 times more likely to have hypothermia than age greater than $24 \mathrm{~h}(\mathrm{AOR}=2.26,95 \% \mathrm{CI}: 1.27$, 4.03). This could be due to the fact that newborns have no adequate adipose brown tissue and had no shivering thermogenesis so they are not capable for thermoregulation. This is similar to a study conducted in Bangladesh, (AOR $=2.23$ 95\% CI: 1.22, 4.0) [9].

Preterm Neonates were 4.8 times more likely to have hypothermia when compared to term Neonates $(\mathrm{AOR}=$ 4.81, 95\% CI: $2.67,8.64)$. The possible reason might be preterm Neonates have immature and thin skin that increase heat loss through radiation, underdeveloped hypothalamic control, they lack efficient neural mechanisms for temperature control by shivering, have decreased glycogen stores, have decreased fat for insulation and have less brown adipose tissue, so they have decreased ability to regulate their body temperature, by producing heat through non - shivering thermogenesis [2, 25, 26]. This is almost similar to a study done in Pakistan in which preterm Neonates were 4 times more likely to develop hypothermia when compared to term newborn [24]. But it is higher than a study conducted in Iran in which preterm Neonates were 1.73 times more likely to be hypothermic than term one [27]. This variation might be due to the difference in the thermal care of preterm newborn, standard of delivery room and NICU.

Neonates who had no skin to skin contact with their mother immediately after delivery were 4.3 times more likely to develop hypothermia when compared with those who have skin to skin contact immediately after delivery $(\mathrm{AOR}=4.39,95 \% \mathrm{CI}: 2.38,8.11)$. The possible reason could be in the utero body temperature of the fetus is consistent with maternal temperature; Neonates who had skin to skin contact immediately after delivery with their mother gain heat through conduction which is consistent with their temperature in the womb during exposure of the newborn to extra uterine environment [28]. This finding is almost similar with a study conducted in Gondar, North west Ethiopia in which those who had no skin to skin contact were 3 times more likely to develop hypothermia [13]. Putting newborn together with the mother or kangaroo mother care is an important means of prevention of hypothermia [29].

Those Neonates who had no early initiation of breastfeeding within one hour after birth were 3.7 times more likely to be hypothermic when compared to those who had started breastfeeding within one hour after birth $(\mathrm{AOR}=3.72,95 \%$ CI: 2.07, 6.65). This might be due to the reason that breast milk is the source of energy or calories to produce heat for thermoregulation and they have no adequate adipose tissue for glucose breakdown which results in hypothermia [25]. And it is consistent 
Table 5 Bivariate and multivariate logistic regression analysis of associated factors among Neonates admitted to Neonatal Intensive Care Unit of Governmental Hospitals in Addis Ababa, Ethiopia, 2016 [ $n=356]$

\begin{tabular}{|c|c|c|c|c|c|}
\hline \multirow[t]{2}{*}{ Variables } & Hypothermic (228) & Non Hypothermic (128) & $\operatorname{COR}(95 \% \mathrm{Cl})$ & AOR $(95 \% \mathrm{Cl})$ & $P$ - value \\
\hline & $N(\%)$ & \multicolumn{4}{|l|}{$N(\%)$} \\
\hline \multicolumn{6}{|c|}{ Age of Neonate (hour) } \\
\hline$\leq 24$ & 171(73.4) & $62(26.6)$ & $3.19(2.02,5.05)$ & $2.26(1.27,4.03)$ & \multirow[t]{2}{*}{$.005^{*}$} \\
\hline$>24$ & $57(46.3)$ & $66(53.7)$ & 1.0 & 1.0 & \\
\hline \multicolumn{6}{|c|}{ Birth weight (grams) } \\
\hline$<2500$ & 127(73.4) & $46(26.6)$ & $2.24(1.44,3.5)$ & $1.33(0.75,2.36)$ & \multirow[t]{2}{*}{0.331} \\
\hline$\geq 2500$ & 101(55.2) & $82(44.8)$ & 1.0 & 1.0 & \\
\hline \multicolumn{6}{|c|}{ Gestational age (weeks) } \\
\hline$<37$ & 155(76.7) & $47(23.3)$ & $3.66(2.32,5.76)$ & $4.81(2.67,8.64)$ & \multirow[t]{2}{*}{$0.001^{*}$} \\
\hline$\geq 37$ & $73(47.4)$ & $81(52.6)$ & 1.0 & 1.0 & \\
\hline \multicolumn{6}{|c|}{ skin to skin contact } \\
\hline Yes & $71(42.3)$ & 97(57.7) & 1.0 & 1.0 & \multirow[t]{2}{*}{$0.001^{*}$} \\
\hline No & 157(83.5) & $31(16.5)$ & $6.92(4.23,11.32)$ & $4.39(2.38,8.11)$ & \\
\hline \multicolumn{6}{|c|}{ Early initiation of breast feeding } \\
\hline Yes & 45(35.7) & $81(64.3)$ & 1.0 & 1.0 & \multirow[t]{2}{*}{$0.001^{*}$} \\
\hline No & 183(79.6) & $47(20.4)$ & 7.0(4.32,11.38) & $3.72(2.07,6.65)$ & \\
\hline \multicolumn{6}{|l|}{ CPR received } \\
\hline Yes & 76(90.5) & $8(9.5)$ & $7.5(3.48,16.15)$ & $3.65(1.52,8.78)$ & \multirow[t]{2}{*}{$0.004^{*}$} \\
\hline No & 152(55.9) & 120(44.1) & 1.0 & 1.0 & \\
\hline \multicolumn{6}{|c|}{ Obstetric complication during pregnancy } \\
\hline Yes & 62(88.6) & $8(11.4)$ & $5.6(2.59,12.13)$ & $1.43(0.57,3.56)$ & \multirow[t]{2}{*}{0.440} \\
\hline No & 166(58) & $120(42)$ & 1.0 & 1.0 & \\
\hline \multicolumn{6}{|c|}{ Pregnancy type } \\
\hline Single & 190(61.1) & 121(38.9) & 1.0 & 1.0 & \multirow[t]{2}{*}{0.145} \\
\hline Multiple & $38(84.4)$ & $7(15.6)$ & $3.46(1.45,7.99)$ & $2.14(0.77,5.97)$ & \\
\hline \multicolumn{6}{|c|}{ Time of delivery } \\
\hline Day time & $108(56.8)$ & $82(43.2)$ & 1.0 & 1.0 & \multirow[t]{2}{*}{0.352} \\
\hline Night time & $120(72.3)$ & $46(27.7)$ & $1.98(1.26,3.09)$ & $1.32(0.73,2.37)$ & \\
\hline
\end{tabular}

${ }^{*}$ Significant at $p$-value $\leq 0.05$

with a study done in Nigeria but lower than a study done in Gondar, North west Ethiopia in which those who were delayed in initiation of breast feeding were 7.5 times more likely to be hypothermic $[13,18]$. This difference in magnitude might be due to difference in study setup, knowledge of mothers on good positioning and attachment of breast feeding and difference in place of delivery.

Neonates who had resuscitation at birth were 3.6 times more likely to be hypothermic when compared to those who had no resuscitation ( $\mathrm{AOR}=3.65,95 \% \mathrm{CI}$ : 1.52 , 8.78). This is due to the fact that Neonates who need resuscitation are those who had birth asphyxia; there is no enough oxygen which is needed for mitochondrial oxidation in the brown adipose tissue, for heat production. And during resuscitation at birth temperature control may not be properly taken care of; during emergency condition resuscitation may be done without wrapping the baby and in cold table. This finding is higher than study done in Bangladesh in which Neonates that had resuscitation were 2 times more likely to be hypother$\operatorname{mic}(\mathrm{AOR}=2.15,95 \%$ CI:1.4-3.32) [9] and a study done in Iran in which those who had resuscitation at birth were almost 2 times more likely to be hypothermic (AOR $=1.91, p$ value $=0.001)$ [27]. This variation may be due to the difference in thermal care practice during resuscitation, warm resuscitation or not and difference in time of resuscitation.

In bivariate analysis, low birth weight was statistically significant with the onset of hypothermia but in multiple logistic regression analysis it was not significant but there was a high prevalence of hypothermia among low 
birth weight neonates 127 (73.4\%) compared with 101 (55.2\%) normal birth weight. This is consistent with a study done in Pakistan 58.1\%, Nigeria 89.1\% and Gondar, Northwest Ethiopia 58 (89.2\%) [13, 18, 24].

\section{Limitation of the study}

Even though the study was conducted in multiple Hospitals, it was done with small sample size and it was conducted with short period of time or in one season so factors like climatic changes or seasonal variations were not addressed.

\section{Conclusions}

The prevalence of Neonatal hypothermia among Neonates admitted to Neonatal Intensive Care Unit of Public hospitals in Addis Ababa was high 228 (64\%). Preterm delivery, age of newborn $\leq 24 \mathrm{~h}$, and absence of skin to skin contact with their mother immediately after delivery, delayed in early initiation of breastfeeding within one hour after birth and resuscitation at birth were factors that had significant association with Neonatal hypothermia. Therefore attention is needed for thermal care of preterm newborn and on the principle of WHO warm chain especially on early initiation of breast feeding, skin to skin contact and warm resuscitation. It is better to increase the practice of skin to skin contact immediately after delivery which is the effective warm chain principle especially in developing countries in which advanced warming instruments and incubators are not present.

\section{Additional file}

Additional file 1: English version questionnaire, for the assessment of Neonatal Hypothermia and associated factors among Neonates admitted to Neonatal Intensive Care Unit of Public Hospitals in Addis Ababa, Ethiopia. (DOCX $23 \mathrm{~kb}$ )

\section{Abbreviations \\ ${ }^{0} \mathrm{C}$ : Degree centigrade; ${ }^{\circ} \mathrm{F}$ : Degree farhanite; AOR: Adjusted odds ratio; Cl: Confidence interval; CPR: Cardio pulmonary resuscitation; ENBC: Essential newborn care; GA: Gestational age; MDG: Millennium development goal; NICU: Neonatal Intensive Care Unit; RR: Relative risk; SDG: Sustainable development goal; SPSS: Statistical Package for Social Sciences; WHO: World Health Organization}

\section{Acknowledgements}

The authors would like to thank Addis Ababa University for funding this study. Our thanks also goes to for all study participants, supervisors and data collectors for their unreserved efforts and willingness to take part in this study.

\section{Funding}

Addis Ababa University had covered all the costs for data collection instruments, data collection, data entry and payments for supervisors and advisors.

\section{Availability of data and materials}

The data that support the findings of this study are available from the corresponding authors upon reasonable request.

\section{Authors' contributions}

BW was involved in the conception, design, analysis, interpretation, report and manuscript writing; BB and TY were participated in the design, analysis, interpretation and report writing. FH was involved in designing the study, analysis, report and manuscript writing. And all authors have read and approved the final manuscript

\section{Ethics approval and consent to participate}

Ethical approval was obtained from Institutional Review Board of Addis Ababa University, School of Allied Health Sciences, Department of Nursing and Midwifery and submitted to each Hospital. In addition, Permission was obtained from all hospitals involved in this study, to conduct research on their property: namely; Tikur Anbessa Specialized Teaching Hospital, St. Paul's Hospital Millennium Medical College, Yekatit Hospital Medical College, Gandhi Memorial Specialized Hospital, Zewditu Memorial Hospital, and Tirunesh Beijing General Hospital. All mothers that were involved in the study were asked for their willingness after they became informed about the purpose of the study and confidentiality of all the data. And an Informed written consent was obtained from all mothers of the newborn that were selected for the study. Mother of the newborns provided consent for them to participate in the study, and also they provided consent on behalf of the newborns to participate in the study. The study participants right to withdraw from the study at any time during data collection was respected. In the event of the mother's child being under the age of providing their own consent, written informed consent was received from the child's grandmother on behalf of the mother and child.

\section{Consent for publication}

Not applicable.

\section{Competing interests}

The authors declare that they have no competing interests.

\section{Publisher's Note}

Springer Nature remains neutral with regard to jurisdictional claims in published maps and institutional affiliations.

\section{Author details}

${ }^{1}$ Department of Nursing, College of Health Sciences and Medicine, Wolaita Sodo University, Sodo, Ethiopia. ${ }^{2}$ School of Nursing and Midwifery, College of Health Science, Addis Ababa University, Addis Ababa, Ethiopia. ${ }^{3}$ School of Public Health, College of Medicine and Health Sciences, Hawassa University, Hawassa, Ethiopia.

Received: 13 June 2017 Accepted: 30 July 2018

Published online: 04 August 2018

\section{References}

1. World Health Organization. Thermal Protection of the Newborn: a practical guide. Maternal and Safe Motherhood unit. Geneva: World Health Organization; 2006.

2. Onalo R. Neonatal hypothermia in sub-Saharan Africa : A review. Niger J Clin Pract. 2013;16(2):129-38.

3. United Nations (UN). The Millennium Development Goals Report 2014. New York: United Nations; 2014

4. Central Statistical Agency [Ethiopia] and ICF International. Ethiopia Demographic and Health Survey 2011. Addis Ababa, Ethiopia and Calverton, Maryland: Central Statistical Agency and ICF International; 2012. p. 1-452.

5. Sodemann M, Nielsen J, Veirum J, Jakobsen MS, Biai S, Aaby P. Hypothermia of newborns is associated with excess mortality in the first 2 months of life in Guinea- Bissau, West Africa. Trop Med Int Heal. 2008:13(8):980-6.

6. Mullany LC, Katz J, Khatry SK, LeClerq SC, Darmstadt GL, Tielsch JM. Risk of mortality associated with neonatal hypothermia in southern Nepal. Arch Pediatr Adolesc Med. 2010;164(7):650-6.

7. Kumar V, Shearer JC, Kumar A, Darmstadt GL. STATE-OF-THE-ART neonatal hypothermia in low resource settings : a review. J Perinatol. Nature Publishing Group. 2009;29(6):401-12.

8. Lunze K, Bloom DE, Jamison DT, Hamer DH. The global burden of neonatal hypothermia: systematic review of a major challenge for newborn survival. BMC Med. 2013;11(1):24.

9. Akter S, Parvin R, Yasmeen BHN. Admission hypothermia among neonates presented to neonatal intensive care unit. J Nepal Paediatr Soc. 2013;33(3):166-71. 
10. Mullany LC, Katz J, Khatry SK, LeClerq SC, Darmstadt GL, Tielsch JM. Incidence and seasonality of hypothermia among newborns in southern Nepal Luke. Arch Pediatr Adolesc Med. 2010;164(1):71-7.

11. Zayeri F, Kazemnejad A, Ganjali M, Babaei G, Nayeri F. Incidence and risk factors of neonatal hypothermia at referral hospitals in Tehran, Islamic Republic of Iran. East Mediterr Heal J. 2007;13(6):1308-18.

12. Ogunlesi TA, Ogunfowora OB, Adekanmbi FA, Fetuga BM, Olanrewaju DM. Point-of-admission hypothermia among high-risk Nigerian newborns. BMC Pediatr. 2008:8:40.

13. Seyum T, Ebrahim E. Proportion of neonatal hypothermia and associated factors among newborns at Gondar University teaching and Refferal hospital, Northwest Ethiopia: a hospital based cross sectional study. Gen Med. 2015;03(04):1-7.

14. Bekele, et al. Prevalence of Preterm Birth and its Associated Factors among Mothers Delivered in Jimma University Specialized Teaching and Referral Hospital, Jimma Zone, Oromia Regional State, South West Ethiopia. J Women's Health Care. 2017;6(1)

15. UNICEF Ethiopia. Preterm babies may be saved with simple inexpensive measures [Internet]. Addis Ababa: UNICEF Ethiopia; 2013. Available from: https://unicefethiopia.org/2013/11/16/preterm-babies-may-be-saved-withsimple-inexpensive-measures/.

16. Manani M, Jegatheesan P, DeSandre G, Song D, Showalter L, Govindaswam B. Elimination of admission hypothermia in preterm very low-birth-weight infants by standardization of delivery room management. Perm J. 2013; 17(3):8-13.

17. Central Statistical Agency (CSA) [Ethiopia] and ICF. Ethiopia Demographic and Health Survey 2016. Addis Ababa, Ethiopia, and Rockville, Maryland: CSA and ICF; 2016.

18. Ogunlesi TA, Ogunfowora $O B$, Ogundeyi MM. Prevalence and risk factors for hypothermia on admission in Nigerian babies $<72 \mathrm{~h}$ of age. J Perinat Med. 2009;37(2):180-4.

19. Byaruhanga R, Bergstrom A, Okong P. Neonatal hypothermia in Uganda: prevalence and risk factors. J Trop Pediatr. 2005;51(4):212-5.

20. World Health Orgnatization. Pocket book of Hospital care for children: Guidlines for the mannagment of common childhood illness. 2nd ed; 2013. p. 49-51.

21. Osborn D, Cutter A and Ullah F. Universal sustainable Development goals. Understanding the Transformational Challenge for Developed Countries; report of a study by stakeholder forum. 2015;

22. Fulton C. Improving neonatal mortality in an Ethiopian referral hospital. BMJ Qual Improv Reports. 2013:1-4.

23. Thwala MD. The quality of neonatal inter-facility transport systems within the Johannesburg metropolitan region; 2009. p. 1-75. Available from: Http:/ handle/10539/11031

24. Ali R, Mirza R, Qadir M, Ahmed S, Bhatti Z, Dema S. Neonatal hypothermia among hospitalized high risk newborns in a developing country. Pak J Med Sci January. 2012;28(1):49-53.

25. Knobel RB. Fetal and neonatal thermal physiology. Newborn Infant Nurs Rev. 2014;14(2):45-9.

26. Lunze $\mathrm{K}$, Hamer DH. Thermal protection of the newborn in resource-limited environments. J Perinatol Nature Publishing Group. 2012;32(5):317-24.

27. Zayeri F, Kazemenejad A, Ganjali M, Babaei G, Nayeri F. Incidence and risk factors of neonatal hypothermia at referal hospitals in tehran, islamic republic of Iran. East Mediterr Heal J. 2007;13(6):1308-18.

28. Waldron S, Mackinnon R. Neonatal thermoregulation. Journal of Infant. 2007; 3(3):101-6

29. Lawn JE, et al. Kangaroo mother care to prevent neonatal deaths due to preterm birth complications. Int J Epidemiol. 2010;3(1):144-54

Ready to submit your research? Choose BMC and benefit from:

- fast, convenient online submission

- thorough peer review by experienced researchers in your field

- rapid publication on acceptance

- support for research data, including large and complex data types

- gold Open Access which fosters wider collaboration and increased citations

- maximum visibility for your research: over $100 \mathrm{M}$ website views per year

At BMC, research is always in progress.

Learn more biomedcentral.com/submissions 